\title{
Paediatric to adult liver transition services: the state of play in the UK
}

The transition of young adults (YA) from paediatric to adult health services is a challenging time for patients, parents / care providers and health care professionals. This period has a higher prevalence of mental health problems and is associated with high rates of non-adherence. ${ }^{1}$ These factors can have a deleterious impact on physical health and in transplant recipients, on graft survival. Strengthening the continuity of transition care from paediatric to adult services was a key recommendation of the Lancet commission ${ }^{2}$ and yet there are no UK guidelines for the transition of YAs with liver disease. A US survey among adult liver transplant physicians reported that less than a third of YAs arrived at their first adult clinic appointment with adequate knowledge about their condition and poor adherence was found to be a frequent barrier to successful transition. ${ }^{3}$

We performed a national survey of paediatric to adult transition liver services in the UK using a questionnaire adapted from the US study. ${ }^{3}$ The questionnaire was distributed electronically to 26 secondary and tertiary liver centres in the UK between 22 October 2017 and 12 February 2018. In total, eighteen centres (69\%) responded: nine centres had a dedicated liver transition service while 12 had an affiliation with a paediatric centre. Nine centres received more than five referrals/year. The availability of transition services resulted in YAs having adequate knowledge about their condition ( $76 \%$ vs $50 \%$ ), better adherence and less patient/family dependence on the paediatric provider.

Compared with the USA, UK centres were more likely to have a formal transition programme (61\% vs $16 \%$ ) but YAs attending clinic were less likely to have adequate knowledge about their condition and were more likely to attend with a parent or guardian. In the UK, there appeared to be adequate communication with paediatric providers. The main barriers to a successful transition in the UK were poor adherence and ongoing dependence on the paediatric providers. YAs in the UK appeared to be more likely to discuss the impact of their condition independently, ie without their parent or guardian. Similarities were noted between the USA and UK with regard to parents/guardians managing the YA's condition without engaging the YA.

Transition services were available in half of secondary/tertiary adult liver centres who responded to an online questionnaire and, within these centres, nearly two-thirds have a documented formal transition programme. However, the constituents of the multidisciplinary team varied hugely among the centres and a more standardised approach would be of benefit to YAs. Neurodevelopment and higher brain executive functions continue to develop in YAs well into their twenties and therefore, transition services can be an important resource for YAs diagnosed with de novo liver disease. ${ }^{4}$

\begin{tabular}{|c|c|c|}
\hline & USA $(n=236)$ & UK $(n=18)$ \\
\hline Formal transition programme & $16 \%$ & $61 \%$ \\
\hline No transition strategy & $32 \%$ & $22 \%$ \\
\hline \multicolumn{3}{|l|}{$\begin{array}{l}\text { Characteristics of YA } \\
\text { attending clinic appointment }\end{array}$} \\
\hline $\begin{array}{l}\text { Have adequate knowledge } \\
\text { about their condition }\end{array}$ & $70 \%$ & $62 \%$ \\
\hline $\begin{array}{l}\text { Arrived to the appointment with } \\
\text { parent/guardian }\end{array}$ & $66 \%$ & $76 \%$ \\
\hline \multicolumn{3}{|l|}{ Barriers to transition } \\
\hline $\begin{array}{l}\text { Inadequate communication } \\
\text { with paediatric provider }\end{array}$ & $61 \%$ & $11 \%$ \\
\hline $\begin{array}{l}\text { Patient/family dependence on } \\
\text { paediatric provider }\end{array}$ & $46 \%$ & $67 \%$ \\
\hline Poor adherence & $72 \%$ & $56 \%$ \\
\hline $\begin{array}{l}\text { Patients lack the capability } \\
\text { to discuss the impact of their } \\
\text { condition independently } \\
\text { without the help of their } \\
\text { parent/guardian }\end{array}$ & $54 \%$ & $28 \%$ \\
\hline $\begin{array}{l}\text { Parents/guardians manage } \\
\text { their child's condition without } \\
\text { engaging their child }\end{array}$ & $49 \%$ & $44 \%$ \\
\hline
\end{tabular}

The importance of transition services for YAs with liver disease is clearly recognised in the UK but the infrastructure is still lacking. It is time to consolidate and improve current services given the marked deficiencies highlighted by this survey. Adherence remains key and was identified as a significant barrier to transition. Selfmanagement remains an important management strategy to try to improve adherence. Self-management programmes sensitive to the needs of YAs need to continue to develop. In addition, peer support programmes are a unique opportunity to reach out and support YAs. Engagement and support of parents/guardians with the transition process remains critical but this has to be with the engagement of the YA. A national collaborative approach is needed and this work must continue to be a priority for the UK hepatology community. 
DEEPAK JOSHI

Consultant hepatologist, King's College Hospital NHS

Foundation Trust, London, UK

JESSICA DYSON

Consultant hepatologist, Freeman Hospital,

Newcastle upon Tyne, UK

MARK HUDSON

Consultant hepatologist, Freeman Hospital,

Newcastle upon Tyne, UK

JOSH LEVITSKY

Consultant hepatologist, Northwestern University Feinberg School of Medicine, Chicago, USA

MADELEINE HELDMAN

Consultant physician, McGaw Medical Center of

Northwestern University, Chicago, USA

MARIANNE SAMYN

Consultant in paediatric hepatology, King's College Hospital NHS

Foundation Trust, London, UK

\section{References}

1 Hames A, Matcham F, Joshi D et al. Liver transplantation and adolescence: The role of mental health. Liver Transpl 2016;22:1544-53.

2 Williams R, Aspinall R, Bellis $\mathrm{M}$ et al. Addressing liver disease in the UK: a blueprint for attaining excellence in health care and reducing premature mortality from lifestyle issues of excess consumption of alcohol, obesity, and viral hepatitis. Lancet 2014;384:1953-97.

3 Heldman MR, Sohn MW, Gordon EJ et al. National survey of adult transplant hepatologists on the pediatric-to-adult care transition after liver transplantation. Liver Transpl 2015;21:213-23.

4 Foulkes L, Blakemore SJ. Studying individual differences in human adolescent brain development. Nat Neurosci 2018:21:315-23

Address for correspondence: Dr Deepak Joshi, Institute of Liver Studies, King's College Hospital NHS Foundation Trust, Denmark Hill, London SE5 9RS, UK.

Email: d.joshi@nhs.net PubMed Central

Both ClinMed and Future Healthcare Journal are now available in PubMed Central, a web-based, free full-text archive of journal literature for all biomedical and life sciences.

Inclusion of the content back to the very first issue of both journals provides readers with greater access to valuable scholarly content and makes finding articles easier. It also means that journal content is now part of a permanent and freely accessible archive, managed by the National Library of Medicine.

FHJ can be accessed at: www.ncbi.nlm.nih.gov/pmc/journals/3619 Clin Med at: www.ncbi.nlm.nih.gov/pmc/journals/2945
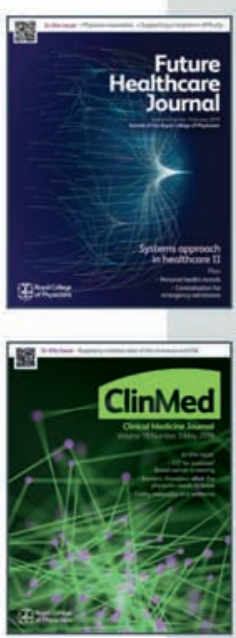